\title{
The Role of Genetic Diversity to Enhance Ecosystem Service
}

\author{
Jemal Mohammed \\ Crop and Horticulture Biodiversity Directorate, Ethiopian Biodiversity Institute, Addis Ababa, Ethiopia
}

Email address:

jemalm781@gmail.com

\section{To cite this article:}

Jemal Mohammed. The Role of Genetic Diversity to Enhance Ecosystem Service. American Journal of Biological and Environmental Statistics. Vol. 5, No. 3, 2019, pp. 46-51. doi: 10.11648/j.ajbes.20190503.13

Received: July 31, 2019; Accepted: October 21, 2019; Published: October 25, 2019

\begin{abstract}
Genetic diversity serves as a way for populations to adapt to changing environments. With more variation, it is more likely that some individuals in a population will possess of alleles that are suited for the environment. Ecosystem services is the benefits people obtain from ecosystems both natural and managed. In the large majority of cases a positive relationship is found between species diversity and ecosystem service provisioning which is genetic diversity is subset of biodiversity. The objective of this review is to provide information about the importance of genetic diversity in plant, animal and microbial in increment of ecosystem service. Genetic diversity have many advantage in crops, which include reduce the danger of genetic uniformity. The other and the more importance of genetic diversity is that give choice of genetic material for farmers and breeders that they select important genes for disease resistant, high yielder, good test, good agronomic character and reduce the impact of climate change. Animal genetic resources include all species, breeds and strains that are of economic, scientific and cultural interest to humankind for agriculture, both now and in the future. These genetic diversity allows farmers to select stocks or develop new breeds in response to changes in the environment, threats of disease, market conditions and societal needs, all of which are largely unpredictable. The third part of genetic diversity is the diversity of microbial, which give us a lot of ecosystem service, which more related to the regulation and support than provision and cultural. Finally, I recommend that, it is better to use this valuable resource in responsible manner to compete the impact of climate change and everincreasing population growth.
\end{abstract}

Keywords: Biodiversity, Climate Change, Ecosystem Service, Genetic Diversity

\section{Introduction}

Biological diversity means the variability among living organisms from all sources inter alia, terrestrial, marine and other aquatic ecosystems and the ecological complexes of which they are part; this includes diversity within species, between species and of ecosystems [1]. Genetic diversity is the total number of genetic characteristics in the genetic makeup of a species. It distinguished from genetic variability, which describes the tendency of genetic characteristics to vary. Genetic diversity serves as a way for populations to adapt to changing environments. With more variation, it is more likely that some individuals in a population will possess variations of alleles that are suited for the environment. Those individuals are more likely to survive to produce offspring bearing that allele. The population will continue for more generations because of the success of these individuals [2].
Millennium ecosystem assessment define Ecosystem Services, the benefits people derive from ecosystems. These include, provision service which is the products people obtain from ecosystems; may include food, freshwater, timber, fibres, medicinal plants. Regulation service, the benefits obtained from the regulation of ecosystem processes, including, the regulation of climate, water, and some human diseases. Ecosystem services that are necessary for the maintenance of all other ecosystem services; include, biomass production, production of atmospheric oxygen, soil formation and retention, nutrient cycling, water cycling, and provisioning of habitat. The non-material benefits people obtain from ecosystems through spiritual enrichment, cognitive development, reflection, recreation, and aesthetic experience; including, knowledge systems, social relations, and aesthetic values [3]. 
About 1.75 million species of plants, animals, and microorganisms have been identified out of the 13 million total species estimated by scientists [4]. The services these species provide contribute to the delicately running natural cycles that help make earth habitable to humans and contribute to our way of life in many ways, from providing us food and pharmaceuticals to helping reduce the impact of natural disasters such as floods. Biodiversity positively correlated with ecosystem productivity by a mechanism known as functional complementarity, which states that the more species there are, the more niches are occupied, and thus the greater productivity of the ecosystem [5].

In the large majority of cases a positive relationship is found between species diversity and ecosystem service provisioning. There is sufficient evidence that biodiversity positively affects effectiveness or reliability of ecosystem services. Biodiversity per se either directly influences (experimental evidence) or is strongly correlated with (observational evidence) certain production and regulating services [6]. Also, in some studies mixed effects of biodiversity on ecosystem services have been found, which can be caused by complex interactions between service delivering species. For instance, in some cases the effectiveness of natural pest regulation decreases with increasing biodiversity because the added species predate other pest controlling species or added species form alternative prey so that the aimed pest species is predated less [7].

Mixed effects can also be caused by focusing on aspects of biodiversity and services that are not directly or clearly linked to each other. Pollinator visitation rate was positively affected by biodiversity of pollinators, but fruit set was not. Fruit set is probably affected by more aspects than visitation of pollinators [8]. For some services specific functional traits or even specific key species are important as found for carbon sequestration (leguminous species in grasslands, longlived trees in forests), natural pest regulation (speciesspecific parasitoids) and pollination (wild bee species). Decline of species may already be affecting the effectiveness of ecosystem service, before species have actually disappeared from the species pool [9]. Indeed, especially for natural pest regulation, pollination and cultural services (species-related recreation) abundance of certain species (functional groups) is often linked to effectiveness of ecosystem services [6]. For example, a higher number of insectivorous birds had a positive effect on natural pest regulation [10].

Most of review articles available on literatures are more inclined to the role of biodiversity that give to ecosystem service. Therefore, there is limited information found on the importance of genetic diversity to ecosystem service. This review focus to fill this gab and bring literatures about the importance of genetic diversity (plant animal and microbial) to ecosystem service (provision, support, regulation and cultural service).

\section{Literature Review}

\subsection{The Role of Plant Genetic Diversity for Increases Ecosystem Service}

\subsubsection{Reduce Dangers of Genetic Uniformity}

Industrialized agriculture favours genetic uniformity. Typically, vast areas were planted to a single, high yielding variety a practice known as monoculture using expensive inputs such as irrigation, fertilizer and pesticides to maximize production. In the process, not only traditional crop varieties, but also long established farming ecosystems destroyed. Genetic uniformity invites disaster because it makes a crop vulnerable to attack a pest or disease that strikes one plant quickly spreads throughout the crop.

A principal purpose of the use of genetic mixtures for disease management is to slow the pathogen's spread by slowing the rate and incidence of infection [11] provided the components differ in their susceptibility [12]. Mechanisms involved include: increasing the distance between susceptible cultivars; creating a physical barrier to spore dispersal; decreasing the proportion of susceptible plant tissue; overcoming selection pressure for pathogens to surmount valuable forms of disease resistance; increasing selection in host population for more competitive or more resistant genotypes; increasing competitive interactions among pathogen populations and inducing resistance in the host for subsequent infection [13]. Mixtures have reduced disease severity by $40-80 \%$ in the cases of cereal rusts and powdery mildew [12]. The success of barley mixtures in reducing disease and thus increasing yield have led to the proposed use of mixed soft wheat varieties for energy-efficient feedstock for a possible bioethanol industry in the UK [14].

In 1970 genetic uniformity left the United States maize crop vulnerable to a blight that destroyed almost \$1 000 million worth of maize and reduced yields by as much as $50 \%$. Over $80 \%$ of the commercial maize varieties grown in the United States at that time were susceptible to the virulent disease, Southern leaf blight. Resistance to the blight was eventually found in an African maize variety called Mayorbella. A major catastrophe was averted by incorporating this resistance into commercial varieties [15].

\subsubsection{The Economic Value of Crop Genetic Diversity}

The value of genetic diversity to modern plant breeding is enormous. The United States Government estimates that a 1 percent gain in crop productivity means a $\$ 1000$ million benefit to the American economy. Italian scientists calculate that the benefits of exotic germplasm for a single crop, durum wheat, amount to $\$ 300$ million per year. Not only cultivated species but also the genes from wild relatives are enormously valuable. Between 1976 and 1980, wild species contributed an estimated $\$ 340$ million per year in yield and disease resistance to the farm economy of the United States. In Pakistan, two million cotton bales were lost from 1991 to 1993 due to a crop failure caused by Cotton Leaf Curl Virus. Resistant cotton types were subsequently identified and were used to develop new virus resistant cotton varieties adapted 
to the growing conditions in Pakistan. Morocco was able to release the first Hessian fly resistant durum wheat varieties, derived from interspecific crosses with wild relatives [16].

During the 1970s the grassy-stunt virus devastated rice fields from India to Indonesia, endangering the world's single most important food crop. After a four-year search which screened over 17000 cultivated and wild rice samples, disease resistance was found. Only one population of the species Oryza nivara, growing wild near Gonda in Uttar Pradesh, was found to have a single gene for resistance to grassy stunt virus strain 1. Today, resistant rice hybrids containing the wild Indian gene are grown across 110000 $\mathrm{km}^{2}$ of Asian rice fields [15].

\subsubsection{The Role of Crop Genetic Diversity for Climate Change}

Genetic information held in certain crop varieties is vital to the development of heat, drought, salinity, pests and diseasesresistant, fast-growing, high-yielding new varieties, necessary to combat food insecurity in the face of climate change. Increasing the sustainable use of plant diversity could be the main key for addressing risks to genetic resources for agriculture. There are thousands of crop wild relatives that still need to be collected, studied and documented because they hold genetic secrets that enable them to resist heat, droughts, salinity, floods and pests. Fifty percent of the increase in crop yields in recent years has come from new seed varieties while irrigation and fertilizer account for the other $50 \%$. A recent good example is the fast maturing New Rice for Africa (NERICA) that has transformed local economies in several parts of Africa [15].

\subsection{The Role of Animal Genetic Diversity Increasing Ecosystem Service}

\subsubsection{Economic Value of Domesticated and Related Animals Genetic Resource}

Animal genetic resources include all species, breeds and strains that are of economic, scientific and cultural interest to humankind for agriculture, both now and in the future. Common agricultural species include sheep, goats, cattle, horses, pigs, buffaloes and chickens, but there are many other domesticated animals such as camels, donkeys, elephants, reindeer, rabbits and rodents that are important to different cultures and regions of the world.

Domestic animals supply some $30 \%$ of total human requirements for food and agriculture [17] by providing final and intermediate outputs. These vary from direct food products, such as meat, milk and eggs, to such products as dung, wool, hides and draught power. They can also play an important role as cash reserves in low-income mixed farming systems. It has been calculated that some $70 \%$ of the world's rural poor depend on livestock as a component of their livelihoods. This sector includes 640 million poor farmers in rain fed areas, 190 million pastoralists in arid or mountainous zones; and more than 100 million people in landless households. Animal genetic resource diversity thus contributes in many ways to human survival and well-being.
Animals of different characteristics, and hence outputs, suit differing local community needs.

Livestock provide valuable products, such as hides, wool and manure, that are important both for subsistence and as sources of income for rural communities. Livestock process forage and crop waste, inedible to humans, into nutritionally important food products. Approximately 40 percent of the total land available in developing countries can only be used for some form of forage production. An estimated 12 percent of the world's population lives in areas where people depend almost entirely on products obtained from ruminant livestock cattle, sheep and goats. Centuries of human and natural selection have resulted in thousands of genetically diverse breeds of domestic animals adapted to a wide range of environmental conditions and human needs. Some are resistant to parasites or disease, while others are adapted to humidity or drought or extremes of heat and cold. Animal genetic diversity, represented by this wide range of breeds, is essential to sustain the productivity of agriculture.

Animals account for $19 \%$ of the world's food basket directly, but they also provide draught power and fertilizer for crop production, bringing their overall contribution up to $25 \%$. In addition, livestock serve as a very important form of cash reserves in many of the mixed farming systems. Taking this into account, animals contribute an estimated $30 \%$ of total human requirements for food and agriculture [15].

\subsubsection{Value Animal Genetic Diversity}

The genetic diversity now found in domestic animal breeds allows farmers to select stocks or develop new breeds in response to changes in the environment, threats of disease, market conditions and societal needs, all of which are largely unpredictable. Indigenous livestock breeds often possess valuable traits such as disease resistance, high fertility, good maternal qualities, longevity and adaptation to harsh conditions and poor-quality feed, all desirable qualities for low-input, sustainable agriculture.

The rare Taihu pigs of China, for instance, offer valuable traits for swine breeders worldwide. This group of pigs has thick, wrinkled skin and long, droopy ears. They can use a high proportion of forage foods in their diet. The adult pig has little lean meat whence the Chinese passion for sucking pig. But Taihu pigs reach sexual maturity in just 64 days and are extraordinarily fertile, producing an average litter of 16 piglets compared with only ten for western breeds. Researchers in Europe and the United States are exploring ways to incorporate these beneficial qualities into commercial breeds. A company in the United Kingdom, National Pig Development, has already produced a commercial hybrid of the Meishan, one of seven strains of Taihu pig. Announced in 1992, it combines the fecundity of the traditional Chinese breed with a higher lean meat content.

Thirty percent of Africa's cattle population, approximately 160 million cattle, are at risk from trypanosomiasis a debilitating and frequently fatal disease transmitted by the tsetse fly in 36 African countries covering over 10 million square kilometres. This devastating disease endangers not 
only African milk and meat supplies, but important byproducts and services such as hides, manure, fuel and draught power. Annual losses in meat production alone are estimated at US\$5 000 million.

Several traditional African cattle breeds, among them the small humpless N'Dama, have developed resistance (trypanotolerance) over thousands of years of exposure to the parasite a trait that relatively modern African breeds do not possess. This genetically based resistance offers hope of reducing or controlling the impact of trypanosomiasis. Small numbers of trypanotolerant N'Dama cattle have long been maintained by West African farmers in marginal farming areas. They thrive on low-quality forage and, though less productive than modern breeds of cattle, their high survival and reproductive rates and longevity make them extremely valuable in harsh environments. Using a technique known as "embryo transfer", the population of trypanotolerant N'Dama cattle has already been increased in order to conserve this rare breed, improve its performance and study its disease resistance. The N'Dama's hardiness, heat tolerance and disease resistance have also been recognized. N'Dama cattle have been crossed with the Red Poll, an endangered British breed, to produce the Senepol breed. The Senepol has been introduced successfully in the Caribbean and the southern United States [15].

\subsection{The Role of Microbial Genetic Diversity in Ecosystem Service}

\subsubsection{Biogeochemical Role in Cycling of Matter}

Soil acts as the source of nutrition for the growth of a spectrum of microorganisms, which have remarkable ability to degrade a vast variety of complex organic compounds due to their metabolic versatility. Microbes carry out recycling of phosphorus, oxygen, carbon, nitrogen and sulphur elements and replenish the environment with these by degrading substrates obtained from dead and decaying plant and animal remains. Haack have analyzed various factors that affected the accuracy, reproducibility and interpretation of carbon source utilization patterns of microbial communities. The replenishment is essential on account of reuse of vital elements and hence microbes work as efficient decomposers and scavengers to clean up the biosphere [18].

\subsubsection{Sustainable Land Use}

Microorganisms play a key role in soil fertility including its maintenance. They can act as indicators for assessment of sustainable land use in space and time. A combination and improvement of several concepts of sustainability may help obtain an integrated signal of functional ecophysiology of microbiota. Human encroachments and disturbances such as addition of pesticides affect the microbial components of an ecological niche and thus a simultaneous effect served on biotransformation reaction occurring in soil. Major processes as sulphur oxidation, nitrification and nitrogen fixation are inhibited by pesticide application. Gadd reviewed the metal tolerance of VAM fungi at heavy metal contaminated sites. Large effects of mycorrhizae as in increasing accumulation of
$\mathrm{Cu}, \mathrm{Ni}, \mathrm{Pb}$, and $\mathrm{Zn}$ in grass Ehrhartia calycina have been found, especially at low soil PH. Arsenate tolerance in plants appears to depend on modifications to the $\mathrm{P}$ transport system and the root absorbing capacity. The tolerant genotypes of plant were found to depend on VAM fungi for P uptake and consequent success. Moreover mycorrhizal fungi connect individuals of same or different plant species, enabling direct interactions between the members of a grassland or forest community and consequently mycorrhizal fungal diversity determines plant diversity, ecosystem variability and productivity [19].

\subsubsection{Microbial Products for Agriculture Purposes}

Modern agriculture depends upon heavy input of chemical fertilizers that are produced by using non-renewable and constantly depleting petroleum based feed stocks. Thus use of biofertilizers that involve a spectrum of microbes including members of family Rhizobiaceae, certain actinomycetes as Frankia, cyanobacteria, free-living or loosely associated bacteria as Azotobacter, Azospirillum and certain, phosphate solubilizing fungi help in bioameliorating the important nutrients as nitrogen, phosphate to soil that in turn increases growth and yield of crop plants. Shen has given selective utilization of existing diversity of microbial species and their function, which present opportunities to improve agricultural production. Shen and colleagues have given two successful cases of its application in China; one is use of yield increasing bacteria (YIB), which are a mixture of several wild type bacteria as Bacillus $\mathrm{sp}$. Isolates from natural ecosystem using specific methods. YIB found to promote crop growth and suppress some diseases [20]. Even mycorrhizal fungi increase levels of several resistances inducing inhibitory chemical (polyphenols and terpenes) production in plants. Further, mycorrhizae provide amino acids and hormones, which secreted in high amounts thus increasing longitivity of plants. The diversity of soil microbial communities can be key to the capacity of soils to suppress soil-borne plant diseases. The health of soil can be defined in terms of its microbiological capacity to suppress the activity of plant pathogenic microbes which could be general owing to aseptic activities of a myriad of undefined organisms or specific suppressiveness due to antagonism. The concomitant increase in the population of fluorescent pseudomonads that produce antifungal antibiotic 2,4-diacetyl phloroglucinol (DAPG) in wheat mono-cropping system and thus specific, suppressiveness of take-all disease in wheat that increased the yield [21]. Recently in India, DAPG production by $\mathrm{P}$. fluorescens was reported to suppress rice bacterial blight.

\subsubsection{Biodegradation of Xenobiotics}

Human kind is increasingly using pesticides as BHC, DDT, 2,4-D,2,4,5-T for getting rid of unwanted weeds, insect pests or pathogenic microorganisms. Removing chemical from the environment can be achieved by ease and in environmentfriendly manner by biological methods that involve use of microbes and plants to degrade a xenobiotic compound and thus decontamination of the polluted site (Bioremediation) or purification of hazardous wastes in water (Biotreatment). 
Biological treatments are more effective as these methods convert toxic chemicals to less toxic ones and possess a significant degree of self-regulation. Microorganisms have diverse capacities to biotransform and, in some cases, to completely destroy toxic chemicals in our environment. Since these transformations alter the chemistry of the hazardous chemical, they may also alter toxicity, environmental fate, and bioaccumulation potential. Several halogenated chemicals such as the chlorinated aromatic compounds, which are major contaminants, nitroaromatics and other conjugated hydrocarbons-polluted contaminated sites could be reclaimed by use of the vanguard organisms isolated from contaminated sites by enrichment cultures. Spingomonas paucimobilis BPSI-3 that was isolated from PCB contaminated soil was observed to degrade halogenated PAHs and biphenyls. Head and Swannell reported bioremediation of petroleum hydrocarbon contaminates in marine habitats by anaerobic hydrocarbon metabolism via bioaugmentation and stressed to reject the approach of nutrient amendment as it can potentially exert as oxygen demand due to biological ammonia oxidation [22]. Samanta have detailed the role of Ralstonia sp for the polycyclic aromatic hydrocarbon degradation [23].

Evdokimova have shown that though microbial diversity decreases in copper, nickel, cobalt and sulphur compound contaminated sites in Kola Peninsula, still the spectrum of fungi, bacteria and actinomycetes were found to bioconcentrate these heavy metals by volatilization or accumulation in cell capsules etc. Ps. flourescens AF39 accumulated heavy metals such as nickel and others and the whole process observed to be rapid and $\mathrm{pH}$ dependent [24].

\section{Conclusion}

Biodiversity is the number of different species of plants, animals, and microorganisms, genetic diversity is one part of biodiversity. Genetic diversity encompass plant, animal and microbial genetic diversity. Ecosystem service is the service we get from the ecosystem which include provisions, support, regulation and cultural. Genetic diversity contributes to agricultural productivity such as a source of disease or pest resistance and high yielder varatiies /breeds. In addition, it helps to adapt the impact of climate change through provision early mature, drought and moisture stress resistant genotypes. The other important genetic diversity is the microbial, which is vast and have a lot of application in agriculture, industries, food processing, and pharmaceuticals. Therefore, we have to keep, use and manage those noble resources in sustainable manner and transfer to the next generation for changing climate.

\section{References}

[1] USGS, 2011. U.S. Geological Survey. Introduction to Genetic Diversity.

[2] CBD (1992) Convention on Biological Diversity, Rio de
Janeiro, Argentina. Convention on Biological Diversity, $\mathrm{http}: / /$ www.biodiv.org/convention/.

[3] Millennium Ecosystem Assessment (2005) Ecosystems and Human Wellbeing, Volume 1, Current State and Ternds. Island Press, Washington.

[4] Sustaining life on earth: How the convention on biological diversity promotes nature and human well-being. (2000). Secretariat of the Convention on Biological Diversity.

[5] Wilby, A. and Hector, A., 2001. The role of biodiversity. e LS.

[6] Harrison, P. A., Berry, P. M., Simpson, G., Haslett, J. R., Blicharska, M., Bucur, M., Dunford, R., Egoh, B., GarciaLlorente, M., Geamănă, N. and Geertsema, W., 2014. Linkages between biodiversity attributes and ecosystem services: a systematic review. Ecosystem Services, 9, pp. 191-203.

[7] Letourneau, D. K., Jedlicka, J. A., Bothwell, S. G. and Moreno, C. R (2009) Effects of natural enemy biodiversity on the suppression of arthropod herbivores in terrestrial ecosystems. Annual Review of Ecology, Evolution, and Systematics, 40, pp. 573-592.

[8] Ricketts, T. H., Regetz, J., Steffan-Dewenter, I., Cunningham, S. A., Kremen, C., Bogdanski, A., Gemmill-Herren, B., Greenleaf, S. S., Klein, A. M., Mayfield, M. M. and Morandin, L. A (2008) Landscape effects on crop pollination services: are there general patterns?. Ecology letters, 11 (5), pp. 499515 .

[9] Isbell, F., Calcagno, V., Hector, A., Connolly, J., Harpole, W. S., Reich, P. B., Scherer-Lorenzen, M., Schmid, B., Tilman, D., Van Ruijven, J. and Weigelt, A., 2011. High plant diversity is needed to maintain ecosystem services. Nature, 477 (7363), p. 199.

[10] Koh, L. P (2008) Can oil palm plantations be made more hospitable for forest butterflies and birds?. Journal of Applied Ecology, 45 (4), pp. 1002-1009.

[11] Mundt, C. C (2002) Use of multiline cultivars and cultivar mixtures fordisease management. Annu. Rev. Phytopathol. 40, 381-410.

[12] Wolfe, M (1985). The current status and prospects of multiline cultivars and variety mixtures for disease resistance. Annu. Rev. Phytopathol. 23, 251-273.

[13] Jarvis, D., Brown, A., Imbruce, V., Ochoa, J., Sadiki, M., Karamura, E., Trutmann, P., Finckh, M (2007) Managing crop disease in traditional agroecosystems: the benefits and hazards of genetic diversity. In: Jarvis, D. I., Padoch, C., Cooper, H. D. (Eds.), Managing Biodiversity in Agricultural Ecosystems. Rome, Columbia University Press and Bioversity International, New York, pp. 292-319.

[14] Swanston, J., Newton, A (2005) Mixtures of UK wheat as an efficient and environmentally friendly source for bioet Zhanol. J. Ind. Ecol. 9, 109-126.

[15] http://www.fao.org/docrep/004/V1430E/V1430E04.htm/ accessed September 2018.

[16] Near East and North Africa Regional Synthesis of Plant Genetic Resources for Food and Agriculture, 2008

[17] FAO. (1999). Food and Agriculture Organization. Women: users, preservers and managers of agrobiodiversity (available at www.fao.org/FOCUS/E/Women/Biodiv-e.htm). 
[18] Haack SK, Garchow H, Klug MJ, Forney LJ (1995) Analysis of factors affecting the accuracy, reproducibility, and interpretation of microbial community carbon source utilization patterns. Appl Environ Microbiol 61: 1458-1468.

[19] Gadd, G. M (2010) Metals, minerals and microbes: geomicrobiology and bioremediation. Microbiology, 156 (3), pp. 609-643.

[20] Shen, H., Zhang, L., Liu, M. and Zhang, Z (2012) Biomedical applications of graphene. Theranostics, 2 (3), p. 283.

[21] Raaijmakers JM, Weller DM (1998) Natural plant protection by 2,4- diacetyl-phloroglucinol-producing Pseudomonas spp. in take-all decline soils. Mol Plant Microbe Interact 11: 144152 .
[22] Head, I. M., \& Swannell, R. P. (1999). Bioremediation of petroleum hydrocarbon contaminants in marine habitats. Current opinion in biotechnology, 10 (3), 234-239.

[23] Samanta, S. K., Bhushan, B., Chauhan, A. and Jain, R. K (2000) Chemotaxis of a Ralstonia sp. SJ98 toward different nitroaromatic compounds and their degradation. Biochemical and biophysical research communications, 269 (1), pp. 117123.

[24] Evdokimova, G. A. (2000). The impact of heavy metals on the microbial diversity of podzolic soils in the Kola Peninsula. Forest dynamics in heavily polluted regions. Report No. 1 of the IUFRO Task Force on Environmental Change., pp. 67-76. 